\title{
IS ARTIFICIAL INTELLIGENCE THE NEW TALENT IN HUMAN RESOURCES?
}

\section{PRATIKSHA JAWALKAR}

Masters in Business Administration (Human Resource), Symbiosis Institute of International Business - Hinjewadi, Symbiosis International (Deemed) University - Pune, Maharashtra, India.

Innovations are a never-ending process in this technological world and they have impacted our lives in many unknown ways. The world is changing so fast that the organizations have to remain up to date in order to survive in this competitive world. Adding to that, Human Resources (HR) is considered to be an integral part of every organization as it mostly deals with people and people is the most important asset of any organization. The most important function in HR is Recruitment, as it brings skills and knowledge of the young and experienced candidate to the organization. Over the decades, there have been many technological advancements all over the world. One of the technological advancements that is most spoken and implemented in many fields is Artificial Intelligence (AI). AI has been a part of our life as Siri and Alexa but now, it is taking over the field of HR as well. Implementing AI in HR does not necessarily mean that it will take over HR managers completely. It means that it will help the managers to take strategic decisions and reduce the manual stress of doing certain tasks and also improves their performance.

This study aims to explain how AI is currently working in some fields of HR and why some people still prefer going the traditional way. The main reason for choosing this topic was that AI is the future of HR. Many jobs in the future will be replaced and also created with the help of AI. As the HR department will revolve around AI in the near future and as we will somehow be associated with it, the researcher thought learning more about AI will help.

The researcher decided to go with primary data and took a sample of 61 people who are either pursuing their career in HR or wish to. The data was gathered via an online questionnaire which clarified whether people are aware about the implementation of AI in various fields of $H R$, do they feel AI is the future of $H R$.

The results suggested that most of them were aware and they think AI is the new talent in HR. But they also feel that AI needs improvement in many areas in order to take over HR. but human touch will always be present.

The research limits its focus on people related to the fields of HR only because the research study was based on detailed HR fields and it helped the study with thorough insights on AI in HR.

KEY WORDS: Artificial Intelligence, Human Resources, Recruitment, Performance.
\end{abstract}

Received: Jun 08, 2020; Accepted: Jun 28, 2020; Published: Sep 16, 2020; Paper Id.: IJMPERDJUN20201276

\section{INTRODUCTION}

Artificial Intelligence, also called as Machine Intelligence, is a tool that uses human intelligence in numerous fields and it is used in all industries to improve productivity and performance. It is a software which can think intelligently, just like a human brain does. It tries to think and act like a human and rationally. Computer science defines Artificial Intelligence as 'Intelligence Agents'. It is actually referred to as the efforts taken to make a machine think sense. AI has not been invented in these recent years. It has been evolved since decades with the efforts of the brightest minds. One might wonder, what is the difference between AI and ordinary software? The 
difference is somewhat in the name. Intelligence. Ordinary software work as told; they don't do anything new. But AI actually processes a huge quality of data faster by using advanced algorithm. Some AI technologies give stability and provide accuracy in the tasks given to them.

Human Resources is a very important department in any organization. It deals with maintaining people in the organization despite of their attitudes and qualities. It has many fields such as recruitment, learning and development, HR Analytics, training, selection. It also deals with payroll, performance appraisal, compensation management. Employees' productivity is achieved with the help of HR. Constantly appraising them encourages them to do their best and hence, achieve organizational goals. The employees should know the purpose of the organization, its mission and vision. Recruiting the right talent also plays an important part in the development of any organization. HR is actually a glue that keeps the organization together.

Gen $\mathrm{Y}$ is very fortunate for Automation in various fields of science, business and now HR too. A mundane job, once done manually can now be performed by machines and software. AI actually plays a very important role in Human Resource Management. It reduces the workload of the managers by doing repetitive tasks with human intelligence. We have actually reached a stage where AI's capabilities have reached such levels that it affects the way businesses are operated. AI is currently used in various fields of HR such as recruitment, appraisal, learning and development, etc.

\section{Recruitment}

Hiring the best candidate decides the future of the company. Recruitment is one of the most critical fields of HR. it is a field that has many repetitive, time consuming and data driven tasks. AI has a lot of potential in helping the recruiters pick out the best candidate. The use of AI teams helps the recruiters screen and analyse the resumes and shortlists the best candidates. It compares those resumes with the resumes of the existing employees with similar job roles and selects the candidates accordingly. As there is no human intervention, human bias does not play a role here. Although, some companies are still facing problems with implementing AI-based software because of the cost associated with it. Previously, it used to take a lot of time for the recruiters to manually screen the resumes and choose the best one amongst them. But, the use of AI Integrated systems is slowly changing the future of HR and its implementation saves time. Some reports have said that the talent acquisition systems have eliminated almost $75 \%$ of the manual work done by recruiters. Posting job openings on websites such as LinkedIn, Naukri, indeed is a long process but with AI, these websites uses machine learning algorithms and searches for keywords, their connections, etc. AI also ranks the suitable candidates according to who is most right for the job so that the recruiters can then decide who they want to call for an interview.

\section{Training}

The organizations design a training program for the newly hired candidates. They do not have any pre-defined parameters. Most of the organizations don't even know how to train their employees. They do not have proper training programmes. Most of the trainers have argued that whatever the trainees learn in their training programmes, half of them seem to be wasted, i.e. either forgotten, inappropriately applied. But now, with the help of AI, training programmes are conducted appropriately. They have a structure to their programme, if anytime any candidate feels that somethings need to be repeated, they can review that particular session again. Not only this, the AI software also provides information about that particular candidate such as their skills, behaviours, attitudes towards other employees working at different levels. It also records the improvement of the trainees and provides frequent updates to the trainers. The AI software helps the employer 
and the employee to know about the gaps in the skills, personality, knowledge, etc and also suggest any improvements that can be made. After the training ends, trainees are also asked for feedback on how this software can be improved.

\section{Performance Management}

Performance bias is very common when it comes to performance appraisal, which in turn leads to increased error rate. Most of the managers show biases while appraising employees which affects the relationship of the employer as well as employee. Traditional performance appraisal has been decreasing due to the implementation of the AI software. But now the question is, Will the usage of AI improve the performance of the employees? Some big companies have said yes as they have evaluated the employees' performance after implementing AI based software.

\section{Research Questions}

This study will answer the following questions:

- In which fields on HR is AI being implemented as of today?

- How many people are aware about the implementation of AI in HR functions?

- What are the future expectations from AI in terms of its ability?

- In the next five years, in which fields of HR should AI be implemented?

- Will AI have a significant effect on job opportunities in future?

\section{LITERATURE REVIEW}

In the paper title "The impact of Artificial Intelligence on the HR function". This paper gives us brief information about the future of technology in various department of HR. After a lot of statistical study, the researcher found out that Recruitment will be the most affected area which will be transformed by technology. Machines are good for analytical thinking but not for "elastic thinking". This means that if a machine is given the same problem multiple times, it will give the same output every time. It won't think out of the box like humans. The researcher has also stated some risks for HR in the development of AI. Some of the risks are that systems can create unconscious bias, privacy risk when it comes to confidential data, managers being misled by the system, etc. At the end of the research, the researcher also gave some tips to the HR managers and professionals as to how to tackle the AI challenges. The flaw in this research is that it does not contain any examples of companies that have adopted this AI technology. Also, this research is based on the future aspect of AI. Paper title "Artificial Intelligence in Human Resource Management". In this paper, the researcher has explained the intersection of Artificial Intelligence and Human Resource Management. This paper explains how AI has created fear of loss of jobs among people but how it isn't new because we all have been fearing automation for many decades now. Further, the researcher has also incorporated the function of HR in the world of AI. Various functions of HR such as recruitment, training, performance management and retention comprise of AI techniques. Screening resumes from a large applicant pool, shortlisting the right candidates, conducting digital interviews are some tasks done by AI in recruitment. In performance management, AI checks the company's objectives and efforts of the employees and then rates them on the basis of their performance. The flaw in this research paper is that it does not have any detailed study. Paper Title "Artificial Intelligence in HR". the researcher has jotted down three different types of AI systems, analytical, humaninspired and humanized artificial intelligence. Analytical AI has characteristics of cognitive intelligence and uses learning 
based on past experiences to inform future decisions. Human-inspired AI has cognitive as well as emotional intelligence. Humanized AI has characteristics of all types, i.e. cognitive, emotional as well as social intelligence. Rather than wasting time doing repetitive HR tasks, AI will let the managers and employees focus on more creative and strategic work that will benefit the companies. The researcher also suggested that AI will remove unconscious biases, AI system basically takes a look at the demographics, education, experience, qualifications of a candidate and predicts how well they will perform in their job. The researcher has also discovered some disadvantages of AI systems. They are expensive and there is huge risk of exposure of confidential data. In this paper, the researcher has not focused on various areas which AI has taken over in some companies. Paper title "An exploration of how Artificial Intelligence is impacting Recruitment and Selection process". The researcher has done a questionnaire study regarding AI in recruitment. Many companies took up this questionnaire and were asked questions if they use any AI-based software in screening or hiring process. When asked if they have in-house HRM software or rely on third party, majority of companies said they have their own in house HRM software. Almost 71\% respondents said that Artificial Intelligence eased the hiring process. The researcher also mentioned some concerns relating to AI such as cost, security, maintenance, etc. This research highly revolves around recruitment and no other HR departments. Paper title “To Study Impact of Artificial Intelligence on Human Resource Management”. Paper title "Application of AI in Human Resource Management and Gen Y's Reaction". Paper title "Perception towards Artificial Intelligence in Human Resources Management Practices". Firstly, the researcher has discussed which areas is AI likely to replace. Areas such as teaching, drivers, blue-collar and white-collar jobs, doctors, lawyers. The researcher further discussed which companies have adopted AI in HR and in which areas are AI being used excessively. Some advantages of AI are accessibility of information, scheduling and talent management. The employer as well as employee can access any kind of information from anywhere using this AI-based software. The researcher concluded his research saying that AI is the optimistic opportunity and AI is soon going to be everywhere in HR. The researcher jotted down the problems relating to the implementation of AI in HR and also necessary solutions that are applied currently to overcome such problems. Their study revolves around Gen Y's reaction or perception towards the implementation of AI. The researcher classified the HR professionals into three perception patterns such as HR Tech Evangelist, HR Tech believer and passive HR Tech enthusiast. HR Tech Evangelist are the ones who understand and suggests the company to adopt AI technologies in the field of HR. HR Tech Believer are the ones who feel the need to implement AI in some fields. Passive HR Tech enthusiasts are the ones who know the benefits of implementation of AI in HR but are not that keen to implement it. The study depicted that almost $61 \%$ of the Gen Y's population come under HR Tech Evangelist. the researcher concluded that the young working generation prefer implementation of AI in many HR domains. The researchers conducted a study showcasing the positive perception of employees working in IT companies towards implementation of AI in HR. the study demonstrated that the employees did not perceive AI as a threat to the field of HR. the study also included the factors that restrain the implementation of $\mathrm{AI}$ in HR fields. The employees do not believe that $\mathrm{AI}$ is going to completely augment the workforce of HR. The study also revealed that the organizations should concentrate on implementing AI in human resource management practises such as decision making, training and development, recruitment, performance analysis, etc. The only flaw in this research paper is that the study is conducted with respect to only IT companies based in Chennai.

After reviewing these papers, the researcher could identify some gaps. Most of the papers were based on qualitative research and due to this, there were no statistics that could justify the research. These papers also majorly focused on the impact of Artificial Intelligence on the fields of Human Resources. 


\section{Research Objectives}

The objectives of this study are:

- To know if people are aware about the implementation of AI in the fields of HR.

- To understand the implementation of Artificial Intelligence in the fields of HR.

- To understand the effect of AI on jobs.

- To understand in which fields of HR can AI be implemented in the next five years.

- To know if AI is the new talent in HR.

\section{RESEARCH METHODOLOGY}

- Primary data: For the collection of data, the researcher have made use of the questionnaire method. Questionnaire is a data collection instrument which is used to ask questions to respondents with an aim to secure the desired information where questions are presented and are to be answered by respondents in a written format. Primary data also includes some personal details of the respondents such as name, age, gender, etc. The questionnaire is a combination of yes-no questions, Likert scale questions, etc.

- Secondary data: The data is collected from previous research papers and published journals.

- Sampling Method: The sampling method the researcher chose is non-probabilistic sampling. The researcher had followed Judgement Sampling. The researcher chose this method to identify the respondents based on my judgment of their experience in the HR field. The respondents involved in the study are either HR professionals or wish to pursue a career in HR. Judgment sampling will provide me with accurate answers required for my study. There were 61 respondents and the responses has been showcased in the form graphical representations and the analysis has been given in the Findings and Analysis section

\section{Findings and Analysis}

As mentioned in my research methodology, the researcher prepared a questionnaire to showcase how many people are aware about Artificial Intelligence in HR functions and what is their take on whether AI is the new Talent in HR.

\section{Respondents Had to Mark According to Their Degree of Agreement:}

I consider myself to be knowledgeable about the topic of implementation of AI in various HR functions. 


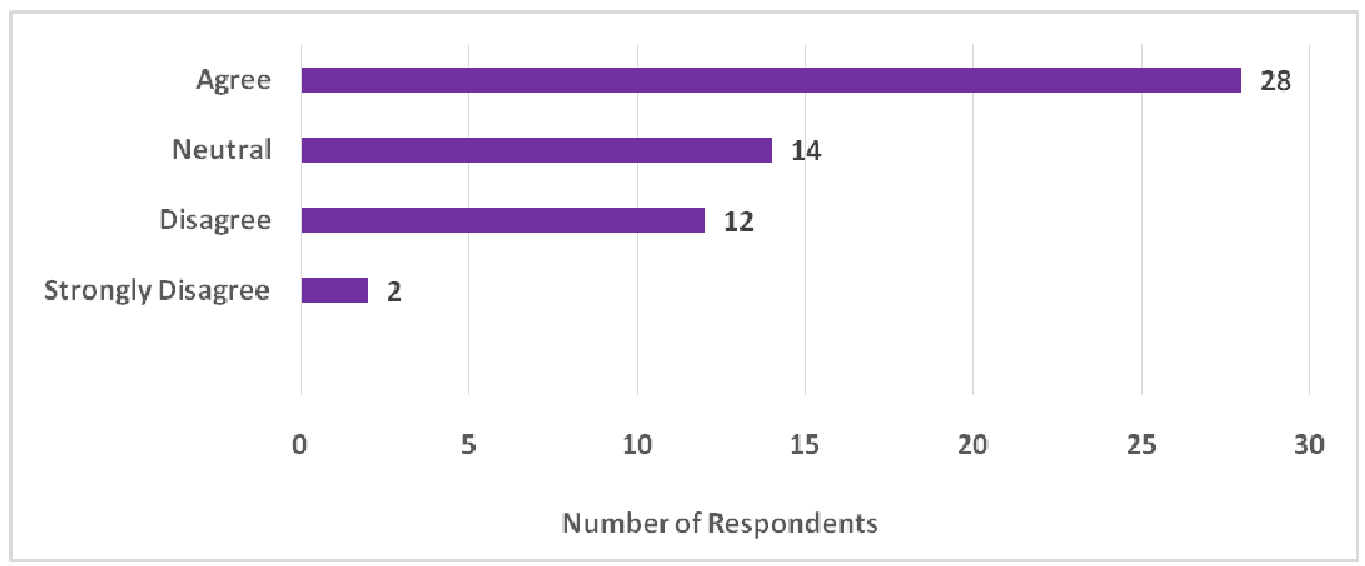

Figure 1

The researcher feel that AI will eliminate the risk of human biases.

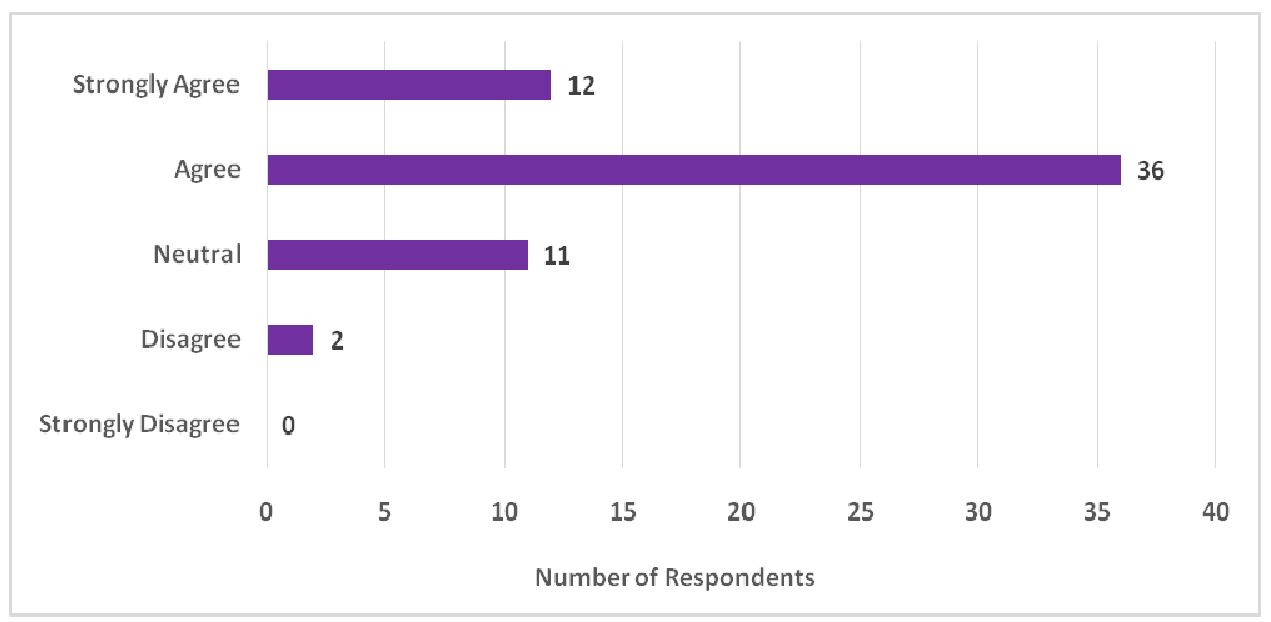

Figure 2

I feel that it will be easier to communicate to a virtual assistant than a human.

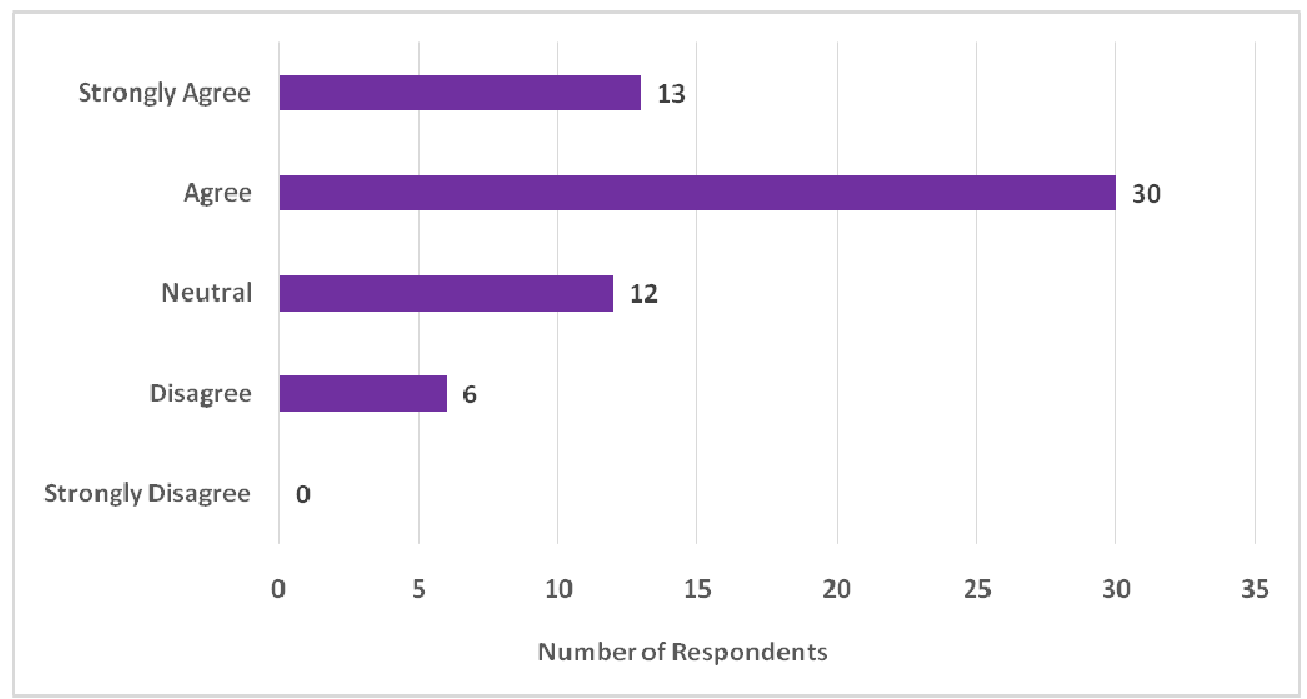

Figure 3

Automation of repetitive tasks will make HR more productive. 


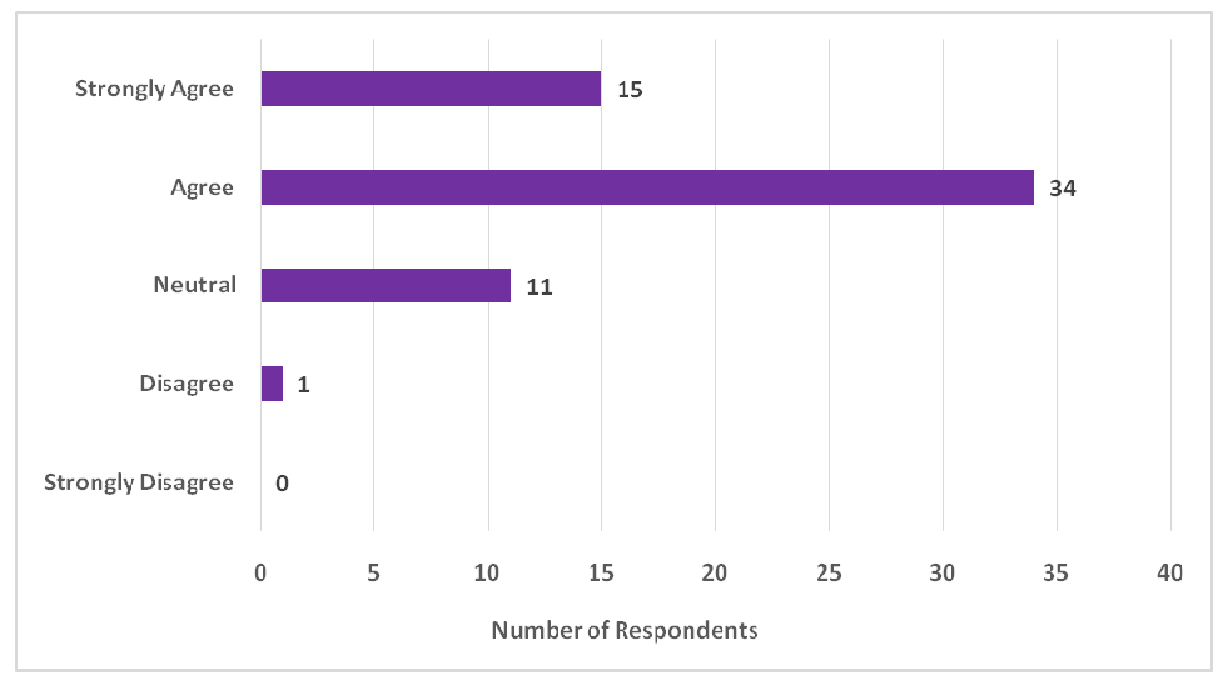

Figure 4

Implementing AI in HR in organizations is cheap.

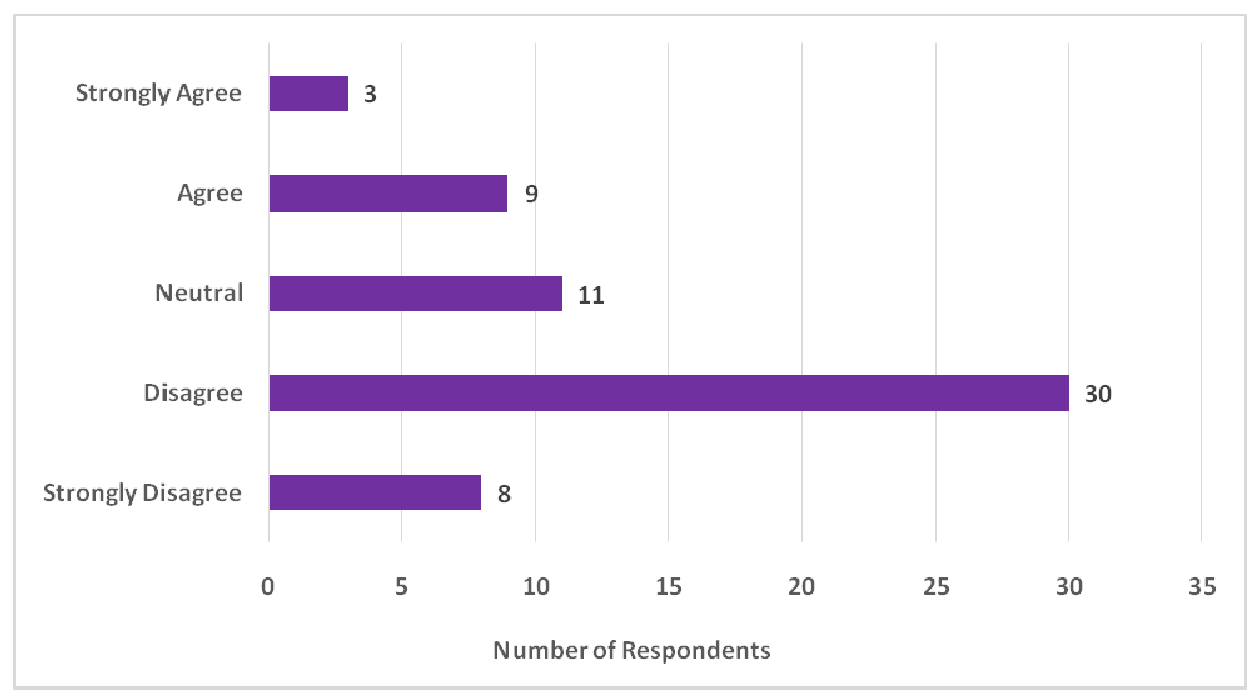

Figure 5

AI interfaces such as chatbots and virtual assistants will become a viable way for employees to get real-time answers to their HR-related questions. 


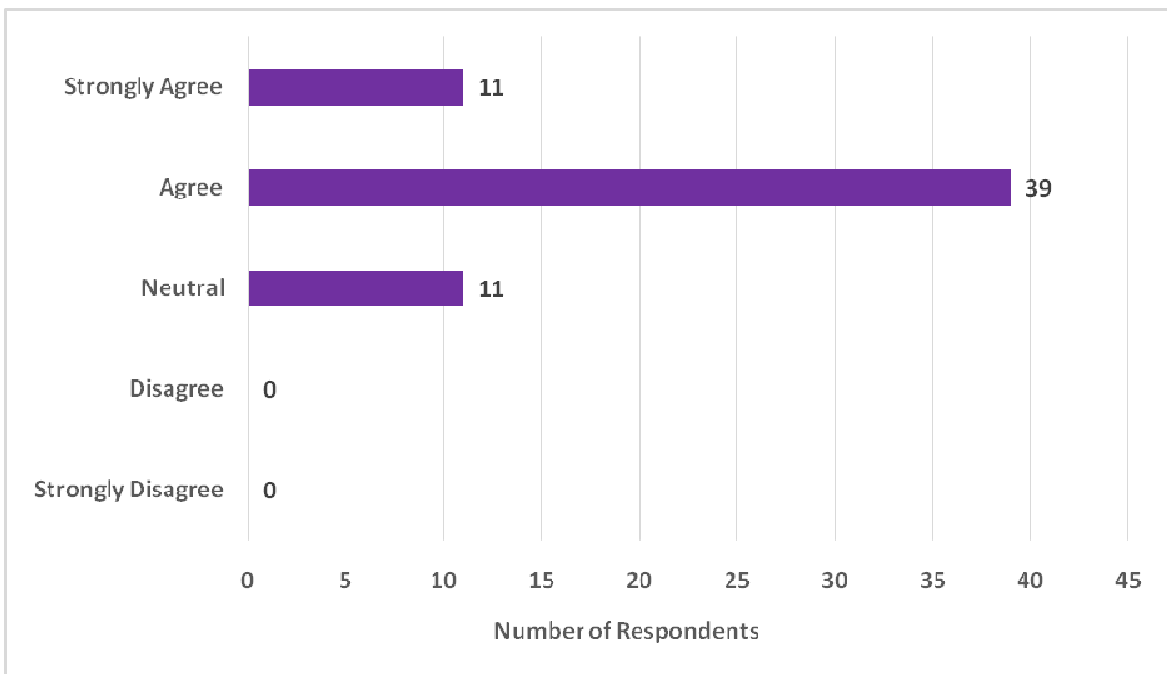

Figure 6

Select the features you would most like to see in an Al-powered HR application? 61 responses

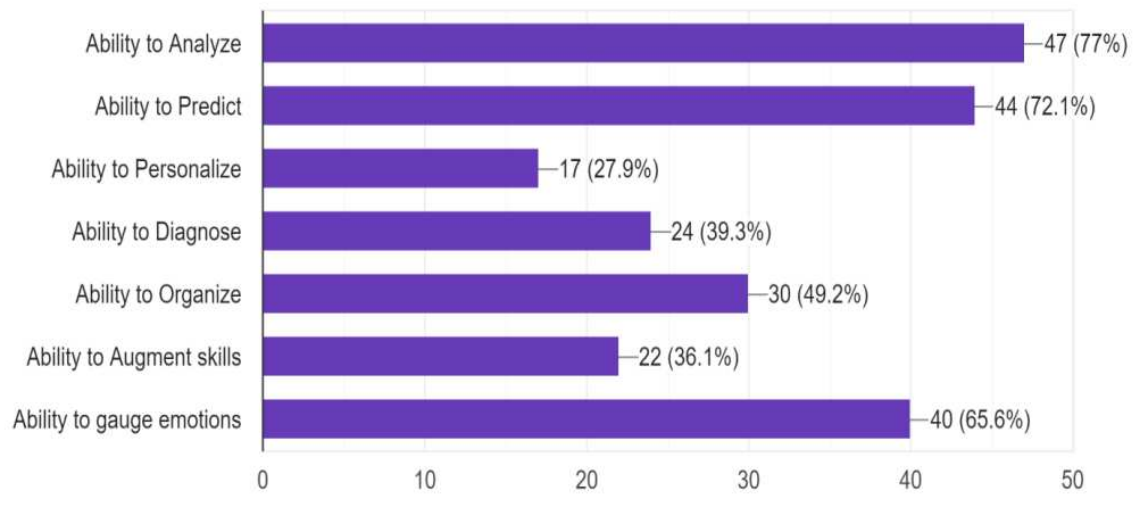

Figure 7 
Select the areas where you think Al has the greatest potential to improve the HR function in the next five years.

61 responses

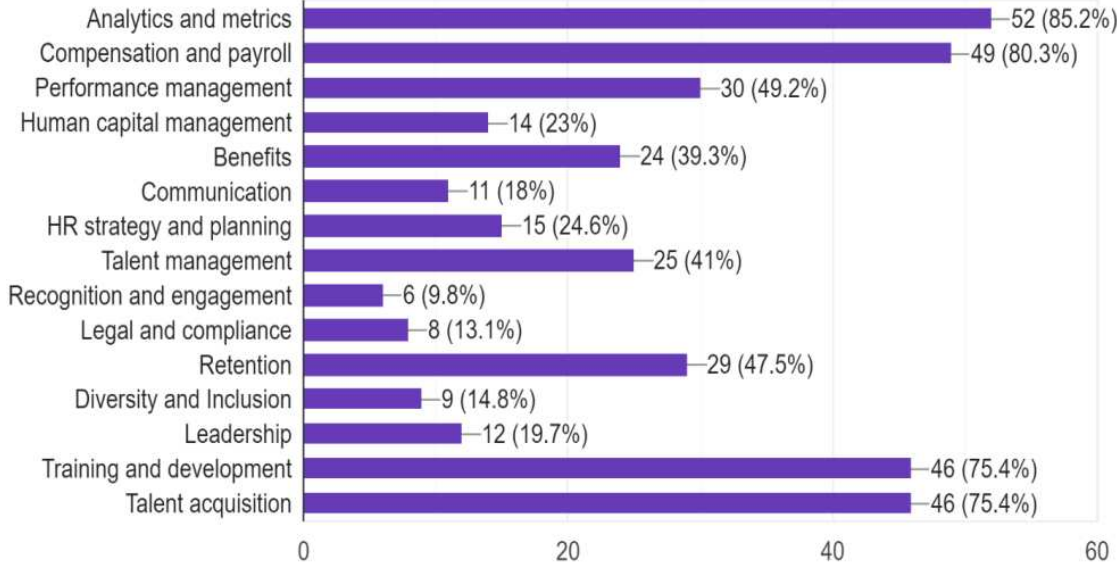

Figure 8

How do you think Al-related technologies will influence the number of jobs in HR in organizations over the next five years?

61 responses

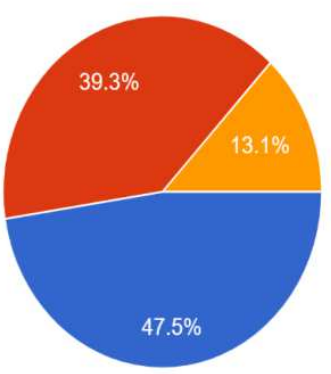

There will be a net loss in jobs

There will be a net gain in jobs

There will not be any significant gain or

loss

Figure 9 
Do you think $\mathrm{Al}$ is the new talent in HR?

61 responses

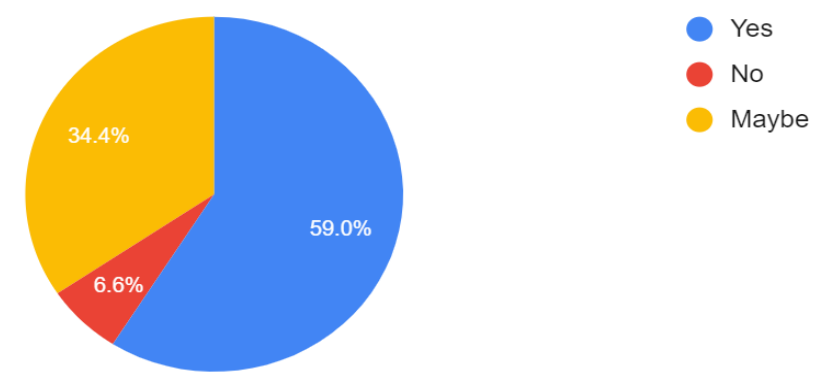

Figure 10

\section{DISCUSSIONS AND IMPLICATIONS}

- Demographics tells us that there were majority of female respondents as the study was entirely based on those working or pursuing HR as a profession. Total 61 responses were recorded, out of which 31 respondents were female and 30 were male. It was also observed that age and profession wise, most of the respondents (27 respondents) were in the age group of 26-30 and are currently working as HR professionals. Following that were the respondents in the age group of 18-25 (22 respondents) and those were mostly students who are currently pursuing HR.

- All the respondents were asked if they were aware about the implementation of AI in the fields of HR and 37 respondents said that they were aware while 9 respondents were not. This means that as AI has not been adopted by a lot of companies, people are not really aware about it.

- Respondents were then asked to mark according to their degree of agreement on some statements. We have come across a very common problem in organizations, that is, human biases. When stated is AI will be able to eliminate human biases in the organization, there were no people who strongly disagree with the fact that AI will eliminate the risk of human biases. 36 respondents agreed with the statement while 11 respondents neither agreed nor disagreed. As most of them agreed with the statement, they believe that AI has the potential of eliminating the risk of human biases in the organizations.

- In our day-to-day life, we always have a fear of being judged when we talk to people about our problems. And in the workplace, communication plays a vital role. When stated if people would be comfortable in talking to a chatbot or virtual assistant, 30 respondents agreed. The reason behind it being they wouldn't have to deal with the fear of being judged when talking to a chatbot. 12 respondents were neutral about it as they won't feel much of a difference while talking to the two. 6 respondents disagree with the statement because they feel comfortable talking to humans than any chatbot or virtual assistant as the human tends to feel emotions which makes the conversation easier. We can infer from the above that AI will be easier to communicate with. 
- As the respondents includes people who are currently working as HR professionals, they have a lot of repetitive tasks to do. They feel that if AI comes into force and does all the repetitive tasks, they will have more time in hand to be productive and explore other fields. This is why, 15 respondents have strongly agreed to the statement stated above. And 34 respondents have agreed. Only 1 respondent has disagreed with the statement and believes that even if AI performs their repetitive day-to-day tasks, it won't be able to make people more productive than they were before AI.

- After the implementation of AI in the workplace, the other additional costs reduce subsequently. But the process of implementation of AI in the organization is very costly. When stated if implementing AI is cheap, 30 respondents disagreed with the statement because they think implementing AI in HR is very expensive. But there are 11 respondents who feel that it is cheap and it should be implemented by all companies.

- Respondents were asked to select the features they would want AI to do. Most of the respondents (47 respondents) opted for Ability to Analyze and 44 respondents opted for Ability to Predict as it is of most importance in today's world. Most of them also feel that the AI should be able to gauge emotions so while making any inferences, it can think from an emotional aspect as well. 30 respondents feel that AI should have the ability to organize while 24 respondents feel that AI should be able to diagnose. These responses tell us that AI needs improvement in some areas and needs to explore some too.

- According to the results in the Findings and Analysis section, 52 respondents said that theythink AI has the potential to take over in Analytics and Metrics. 49 responses feel that AI will take over Compensation and Payroll. 46 respondents feel that AI will take over Training and Development and Talent Acquisition. 29 respondents feel that AI will take over retention and so on.

- Respondents were asked if they think implementing AI in HR fields will make a significant change in the number of jobs. 29 respondents stated that there will be a net loss in jobs as AI will be used to do manual work and in turn eliminate people required to do such jobs. While 24 respondents stated that there will be a gain in the number of jobs even after the implementation of $\mathrm{AI}$ as it will create more job opportunities for people who have the knowledge to operate the automated systems. 8 of the respondents feel that there will neither be an increase nor a decrease in the number of job opportunities as the same people doing their jobs manually might be required to control the AI chatbots and take necessary decisions.

- Finally, the most important question was asked to the respondents and 36 of them said that $\mathrm{AI}$ is the new talent in HR, while 21 respondents were not sure if it is the new talent. And 4 respondents said that they do not think that $\mathrm{AI}$ is the new talent in HR.

- I conclude the paper by stating that, looking at the results, AI is the new talent in HR but it still has many areas to improve and is expected to have the ability to do a lot of HR functions in the next 5 years.

\section{REFERENCES}

1. Anupam Jauhari (2017) "How AI and Machine learning will impact HR practices"

2. Josh Bersin (2018) "Artificial intelligence in HR"

3. Senthiil, P. V., Sirusshti, V. A., \&Sathish, T. (2019). Artificial intelligence based green manufacturability quantification of a unit production 
process. International Journal of Mechanical and Production Engineering Research and Development, 9(2), 841-852.

4. Dr. Surabhi Jain (2018) “HRM and AI"

5. PATEL, A., \& PANDEY, A. PREDICTION OF PLASMA ARC CUTTING PERFORMANCE FOR SS-304 MATERIAL USING ARTIFICIAL NEURAL NETWORK.

6. Peter Reilly (2018) "The impact of Artificial Intelligence on the HR function" https://www.employmentstudies.co.uk/system/files/resources/files/mp142 The impact of Artificial Intelligence on the HR function-Peter Reilly.pdf

7. Ruby Merlin, Jayam. R(2018) “Artificial Intelligence in Human Resource Management” https://acadpubl.eu/hub/2018-119-17/2/153.pdf

8. Dr. Ohwas Ahmed (2018) “Artificial Intelligence in HR” http://www.ijrar.org/papers/IJRAR1944797.pdf

9. Agarwal, A., Gans, J. and Goldfarb, A. (2018). Predictive Machines: The simple economics of Artificial Intelligence. Harvard Business Review.

10. Breaugh, J. A. (2008) "Employee recruitment: Current knowledge and important areas for future research", Human Resource Management Review.

11. Bryndin, E. (2020). Development of sensitivity and active behavior of cognitive robot by means artificial intelligence. International Journal of Robotics Research and Development, 10(1), 1-11.

12. Karan Hiren Bhagat (2019) "An exploration of how Artificial Intelligence is impacting Recruitment and Selection process"

13. Espiritu, J. A. THE LIVELIHOOD RESOURCES, PRACTICES AND VALUES OF AETAS IN MID-BAYTAN, ZAMBALES, PHILIPPINES: IMPLICATIONS TO EDUCATION AND COMMUNITY DEVELOPMENT.

14. https://esource.dbs.ie/bitstream/handle/10788/3956/mba_bhalgat.pdf? sequence=1\&isAllowed=y

15. Dr Jeremy nunn (2019) “Emerging impact of AI on HR" 